\title{
Investigation of the Efficiency of Wet Biodiesel Purification
}

\author{
Viktor Polishchuk, Svetlana Tarasenko, Ievgen Antypov*, Nataliya Kozak, \\ Andrii Zhyltsov, and Andrii Bereziuk \\ National University of Life and Environmental Sciences of Ukraine \\ 03041, Ukraine, Kyiv, Heroiv Oborony Str., 12, phone: +38-044-527-87-48,
}

\begin{abstract}
The main research aim is to verify the efficiency of wet methods of biodiesel cleaning and to establish optimal and rational parameters for biodiesel purification and disposing of its cleaning waste. The efficiency of biodiesel washing was studied by means of volumetric, bubble and aerosol washing. Volumetric washing of biodiesel was carried out with the use of a blade mixer with three blades on a shaft and a four-blade agitator with sloping blades. One of the three methods of biodiesel washing studied can be recommended for practical use - aerosol washing with medium- and large-grained washing to be carried out for at least 4-5 hours, while finegrained - for a longer time. The use of waste from the purification of biodiesel as a cosubstrate in biogas plants will almost double the output of biogas, which will significantly reduce the payback period of biogas plants.
\end{abstract}

\section{Introduction}

Biodiesel is obtained as a result of the alcoholization of vegetable, animal or other fats with alcohols (ethyl, methyl, etc.). The best conversion of fats is noted when using methanol (methanol reaction). The methanol reaction is very slow. For its acceleration, acid or alkaline catalysts are used. The simplest, and hence the cheapest, is methanolysis with a homogeneous catalyst.

\section{Problem statement}

During methanolisys with a homogeneous catalyst, the latter does not enter the reaction itself, but only accelerates it. Therefore the catalyst remains completely in the produced biodiesel, causing engine corrosion. So, in order to produce high-quality biodiesel, one needs to purify it from a homogeneous catalyst. At the same time, it is equally important to address the issue of disposal of its cleaning waste.

\footnotetext{
* Corresponding author: ievgeniy_antypov@ukr.net
} 


\section{Analysis of the recent studies}

Different methods for the biodiesel purification from the catalyst residue have been developed, the main ones are wet (washing) and dry biodiesel purification. Recently, the information on the development of a membrane method for the biodiesel purification has begun to appear.

Wet biodiesel cleaning. The biodiesel catalyst is removed by mixing the latter with acidified water (in case of an alkaline catalyst), which results in neutralization of the catalyst with the formation of acid salts (soaps) that pass into soapstocks. When combined with water, the acid salts form crystalline hydrates, which hang in the biodiesel layer in the form small plates, gradually falling under gravity down to the bottom of reactor. However, the smaller is the size of these plates, the longer is the time they settle down, which can last several days.

Therefore, to accelerate the settling of plates of acid salts, biodiesel is washed with water, which serves as a solvent washing out impurities, leaving pure biodiesel. For this purpose biodiesel is mixed with water in a proportion of 1: 5. Water cleans biodiesel, dissolving pollutants in itself. Water with impurities and biodiesel is divided into phases. Water rinsing is carried out at a temperature of $30^{\circ} \mathrm{C}$. If quality is not achieved during one cycle, rinsing is performed several times. Each washing cycle should be carried out in 45 75 minutes. The rinsing is carried out until the neutral $\mathrm{pH}$ is reached. In this case, the washing water will have to be neutralized with acid before utilization [1].

Wet washing is divided into bubble (foam), aerosol and volumetric.

Foam washing is the careful mixing of $1 / 3$ of water and $2 / 3$ of biodiesel (water precipitates to the bottom, and biodiesel remains on the surface) and air bubbling through the water layer. Air bubbles provide indirect mixing of both liquids - they capture a small amount of water and transfer it through biodiesel, removing soap and other impurities. When the bubble is torn on the surface, the water drops downwards and takes even more soap and admixture down the road. After about 6 hours of washing, the air flow is overlapped and the water is drained, fresh water is added and the process is repeated. These water replacements are carried out three times until the water becomes completely transparent, and the $\mathrm{pH}$ of the water is neutral. Rinsing water can be used many times to rinse the following portions.

The advantages of this technology are that it uses less water compared to other technologies, and use of relatively cheap equipment. The process does not require constant observation. The disadvantages of the technology are inefficient purification of biodiesels of poor quality and small volumes due to the fact that bubbles can mix water and biodiesel very vigorously, which will lead to the formation of an emulsion of two liquids. Emulsion formation is the main problem of washing, but it is also a peculiar form of evaluation of the quality of the process.

Aerosol washing was developed as a way to solve problems with the emulsion formation. In this process, more water and more complex equipment are used. However, this method also masks problems with quality - one can get a "good rinse" visually, but not always have an idea of what happened as a result. At aerosol washing, a system of sprays placed above the biodiesel layer, with the possibility of water drainage after it passes through the fuel. Aerosol washing mixes biodiesel to a lesser degree than a bubble one, and removes soap gradually. Milder mixing means less probability of forming an emulsion of soap, mono- and diglycerides. Many users of this system carry out bubble washing additionally as the final stage - after the soap removal, water and fuel are not so actively emulsified, so the use of bubble washing after aerosol gives a good result. The disadvantages of aerosol washing include increased water consumption, more complex 
equipment and masking of potential problems. Unfortunately, mono- and diglycerides are not removed from biodiesel, regardless of the method of washing - they do not dissolve in water and not washed out with it, and during an aerosol washing one should further control the quality of fuel.

During volumetric washing, the equal quantities of water and biodiesel are mixed, after which they are stirred and settled, the water is drained, and the process is repeated many times. This method is more time-consuming, uses more water and can not be automated like a bubble one.

However, wet cleaning has its drawbacks. This is a long process that takes a long time to clean biodiesel completely. Sometimes seven or eight washing cycles may be required to achieve full transparency. In addition, there is a problem utilizing waste water with dangerous impurities. Together with waste water, a certain part of biodiesel is lost.

As a rule, when washing biodiesel, a combination of washing methods is used: preliminary aerosol washing with a final bubble one; simultaneous aerosol and volumetric washing. For example, the technology of biodiesel production at the American BP-190 plant involves combined double biodiesel washing in aerosol and volumetric ways [2].

Wet purification of biodiesel provides its efficient cleaning from a homogeneous catalyst [3]. However, as noted in [4], [5], wet processes of biodiesel purification require the use of large amounts of water, which, according to [6], [7], generates a huge amount of wastewater, that increases the cost of purification. Thus, in [8], it is argued that wet purification of biodiesel in Thailand produces at least 70,000 liters of polluted sewage a day. The sewage with high $\mathrm{pH}$, significant levels of residual $\mathrm{KOH}$ and fats that inhibit the growth of microorganisms, which complicates the natural purification of sewage waters. In addition to that, as it was stated in the paper [3], the biodiesel purified this way should be further released from water. The use of waste from the purification of biodiesel as a cosubstrate in biogas plants is considered.

Dry purification presupposes the use of an adsorbent which separates impurities from biodiesel. Some systems used ion exchange resins, others - magnesium silicate - a mineral, one of which is sold by Dallas Group of America Inc. under the brand name Magnesol. Volatile clay, activated charcoal, etc. were also used as adsorbents.

Ion-exchange resins are high-tech artificial resins that can capture catalyst molecules on the surface of resin particles. They represent insoluble matrices, usually in the form of small (diameter 1-2 mm) beads of white or yellow color [3]. Biodiesel cleaning presupposes its filtration through a layer of ion-exchange resin, on the surface of which there is a removal of impurities from biodiesel [1], [9].

Nowadays, the following types of ion-exchange resins are produced: bd10dry by "Rohm and Hass Chemical Co" (designed to remove methanol from biodiesel, it does not remove alkaline catalyst), Dowex DR-G8 by "Dow Chemical" (designed to remove salts, soap, glycerine and other organics from raw biodiesel; in addition, dried resin also serves to dry biodiesel, as it captures and retain water), PD-206 by "Purolite" (designed to remove soap and glycerine from biodiesel), Lewatit GF-202 produced by "Lanxess", Tulsion T-45 BD by "Thermax" (removes both glycerine and soap from biodiesel), K 2629, SP 120, SPC 112 by "Bayer AG".

Thus, when purifying the biodiesel with ion-exchange resin PD-206, depending on the degree of pollution, $1 \mathrm{~kg}$ Purolite PD-206 can be used for purification of $16 \mathrm{~m}^{3}$ of biodiesel. During the operation, the resin will swell and may increase in volume by $200 \%$ of the amount during filling. For the normal operation of the purification system, it is necessary to provide a flow with a flow rate of liquid 5-7 $\mathrm{m} / \mathrm{h}$. Depending on the amount of resin used and the amount of biodiesel produced, the service life of the resin is 30-45 days [1], [9]. As indicated in [10], ion-exchange resins can reduce the level of soap in biodiesel from $1200 \mathrm{ppm}$ to 50 ppm and lower. 
Magnesium Silicate (Magnesol) is a fine-grained powder having a uniform particle size (60 $\mu \mathrm{m})$. When purifying the biodiesel, after the glycerine separation and methanol removal, Magnesol is added to it and mixed with an agitator in the reactor for 5-10 min [11]. After purification the mixture is gradually run through the filter with the cell size $5 \mu \mathrm{m}$ and $1 \mu \mathrm{m}$. Purified biodiesel is polished through the filter with the cell size $0,45-0,55 \mu \mathrm{m}$ [3]. In the paper [12] it is noted that purification with the help of Magnesol is more efficient if compared with the neutralization with the help of acidified water and further water washing.

Silica gels are obtained by means of thermal and chemical treatment of silicon dioxide. Their specific surface area is $300-750 \mathrm{~m}^{2} / \mathrm{g}$, the specific total pore volume $-0.28-0.9 \mathrm{~cm}^{3}$ $/ \mathrm{g}$, the bulk weight $-500-800 \mathrm{~kg} / \mathrm{m}^{3}$, the regeneration temperature $-100-200{ }^{\circ} \mathrm{C}$. Alumogels - adsorbents derived from aluminum hydroxide (alumina). Their specific surface area of absorption is $180-200 \mathrm{~m}^{2} / \mathrm{g}$, and other parameters - as in silica gel [13, p. 562-563]. In papers [14] and [15], satisfactory purification of biodiesel by silica gel is noted; in [16] - more efficient treatment of biodiesel with silica gel compared with the washing of biodiesel with hot distilled water.

The use of inorganic materials usually involves adding solids to biodiesel and mixing them. A suspension is formed, and after stirring it within the required time, the purification with the help of filter occurs. When using ion-exchange resins, manufacturers usually install a column filled with dry resin; biodiesel stream passes through the resin until it is saturated. In some cases, one liter of ion-exchange resin can process up to 2000 liters of biodiesel.

Zeolites - Aluminosilicate clays, which contain oxides of alkali and alkaline earth metals, are characterized by a clear regular structure of pores, which, under natural temperature conditions, are filled with water molecules. Zeolites absorb substances into their absorption pores, but not all substances can penetrate and stay there. This is explained by the fact that absorption pores are interconnected by pores of a certain size. Only molecules critical diameter of which is smaller than the pore diameter can penetrate through the pores. By separation principle, zeolites differ from other adsorbents - their absorbate molecules "sift" through the openwork structure of zeolite. In this regard, the zeolites are characterized not by the specific area of the pore surface, but by the volume filling of the adsorbate pores, which is $0.2-0.25 \mathrm{~cm}^{3} / \mathrm{g}$. The bulk density of zeolites is $600-800 \mathrm{~kg} / \mathrm{m}^{3}$. In nature, zeolites are found in deposits of the tufogenous-sedimentary type, which were formed as a result of changes in volcanic tuffs in marine and continental basins.

The use of zeolites in technological processes led to the development of specific requirements to the consumer properties of these absorbents, which were not always consistent with natural zeolites. To meet these requirements, since 1948, work on the synthesis of zeolites has begun. During these years more than 65 different zeolites have been synthesized, most of which have no analogues in nature.

The zeolites structure of 4A and 5A grades consists of large and small (sodalite) absorption pores. The elementary cell has one large and one small pores. The absorption pores of zeolites of 4A and 5A grades are so small that, practically, only water molecules can penetrate them. The zeolites of $10 \mathrm{X}$ and $13 \mathrm{X}$ grades have pores of a large size, which explains their greater absorption capacity in comparison with zeolites of 4A and 5A grades. The $3 \mathrm{~A}$ zeolites at normal temperatures absorb only water in a significant amount. This property has determined their widespread use for dehydration of biodiesel.

Zeolites are used in the form of molecular sieves and membranes. Molecular sieves are zeolite balls, which fill the device through which the gas for purification is passed. Zeolite membranes are used in the form of a thin layer which is put on a ceramic basis, that allows to process with large streams. On an industrial scale, the use of zeolite layer on the inner surfaces of ceramic elements (tubes) is preferred, in order to avoid mechanical damage and to organize optimal flow [17]. In [18], a high efficiency of 5A zeolites for the purification 
of biodiesel from an alkaline catalyst was stated.

Clays (bentonites, diatomites, trepeli, flasks) have worse adsorption properties (specific surface area $-35-150 \mathrm{~m}^{2} / \mathrm{g}$, bulk density $-400-450 / \mathrm{m}^{3}$ ), but they are much cheaper than other adsorbents. In [19], a comparison was made between the purification of biodiesel from the alkali catalyst residues with bauxite, bentonite and enterosgel attapulgite. The treatment with bentonite showed the best results in removing soap.

Activated carbon is obtained from organic raw materials: coal, sawdust, wood, waste from leather, paper and meat production, and others like that. In the process of its production, dry raw material distillation and subsequent activation by steam or chemical reagents are used to obtain a fine structure of the material. The specific surface area of the activated carbon is $600-1700 \mathrm{~m}^{2} / \mathrm{g}$, the micropore volume is $0.3-0.6 \mathrm{~cm}^{3} / \mathrm{g}$, the bulk density is $380-600 \mathrm{~kg} / \mathrm{m}^{3}$. Activated charcoal is used in the form of granules in the size of 1-7 $\mathrm{mm}$ or powders with particles up to $0.15 \mathrm{~mm}$ in size. The structure of activated carbon is even, it is regenerated and used many times. The disadvantages of activated carbon include combustion at temperatures above $300{ }^{\circ} \mathrm{C}$ and high cost [13, p. 562-563]. In [20], a higher efficiency of biodiesel purification with activated carbon is noted.

Most adsorbents must undergo a surface activation procedure before use. This process is the calcination of the adsorbent at a temperature of $500-600{ }^{\circ} \mathrm{C}$ to release the surface from airborne adsorbed moisture and gases.

Dry purification methods are effective, but the cost of Magnesol and ion-exchange resins is quite high, which significantly increases the cost of produced biodiesel. In addition to that, manufacturers of ion-exchange resins recommend not to exceed the concentration of $500 \mathrm{~g} / \mathrm{t}$ of soap in crude biodiesel, otherwise the quality of purification is reduced. Therefore, in order to reduce costs, it is recommended to pre-purify biodiesel with other methods. In addition, if biodiesel is heavily contaminated, ion-exchange resins quickly lose their properties and are poorly regenerated.

Membrane purification of biodiesel. The membrane technology of biodiesel purification is based on the use of its filtration process. All membrane processes have a membrane, which is the main filtering element, and is a semi-permeable partition with a porous structure. The term "semipermeable" means that one substance passes through the membrane and holds the other one. This property is called the selectivity or resolution for the components of the mixture, which is the main property of the membrane.

Through the semipermeable membrane only molecules of the liquid are passed, and all molecules with high molecular weight are delayed. For this, the membrane should have pores of very small size, which makes the process of cleaning on the membrane rather slow, requires high pressure and the use of membranes with a large area of the surface.

The membranes used in these processes, depending on the pore size and the size of the detained particles, can be divided into 4 types: reverse osmosis, nanofiltration, ultrafiltration and microfiltration.

The pore size of the membrane increases from reverse osmosis to microfiltration, which means that the size of the maximum size of the retained particles increases on the surface of the membrane working layer. Moreover, the larger is the pore size of the membrane, the lower is the resistance it creates, and the less pressure is required to ensure the filtration process.

Reverse-osmosis membranes according to selective properties are the most selective and effective as regards the separation coefficient of solutions. They have the smallest pore size (up to 0.001 microns). The average percentage of retention by reverse osmosis membranes is $97-99 \%$ of all dissolved substances. As a rule, they are the finishing stage of cleaning the liquid. Nanofiltration membranes have a pore size of 0.001 to $0.01 \mu \mathrm{m}$, and ultrafiltration 0.01 to $0.1 \mu \mathrm{m}$. The process of ultrafiltration requires an excess pressure of 2 to $10 \mathrm{~atm}$. Microfiltration membranes have a pore size of $0.1-1.0 \mu \mathrm{m}$ and operate at relatively low 
pressure.

Membranes are organic and inorganic. Organic membranes include polymeric membranes. The first polymer used in the manufacture of membranes was cellulose acetate. But its use is limited by the tendency to hydrolysis in alkaline environment [21]. Currently, they are replaced by polyamide, polysulfone, polycarbonate and other polymers. These synthetic polymers improve chemical resistance and have better resistance to degradation by the action of microorganisms. However, in organic solvents, polymeric membranes can swell, which leads to a change in pore size. Therefore, polymeric membranes under the action of solvents have a shorter lifetime [3], usually up to a year [21].

Inorganic include ceramic, metal-ceramic, metallic, graphite and glass membranes. The most commonly used are ceramic and metal ceramic membranes.

Ceramic membranes are used in a wide range of $\mathrm{pH}$ in the presence of aggressive environments and high content of solvents. Ceramic membranes due to brittleness may have a geometric shape only in the form of tubes or multichannel blocks. The consequence of this form and the large wall thickness is very low specific productivity, which leads to higher capital costs for the manufacture of plants (large area of membranes, increased material density, etc.) than when using polymeric membranes. On the other hand, the term of their exploitation is higher.

Metal-ceramic membranes are produced in the form of thin tubular or flat metal-ceramic filters. Metal-ceramic membranes are not fragile and have high mechanical strength with a relatively small thickness (about $250 \mu \mathrm{m}$ with a ceramic layer of about $15 \mu \mathrm{m}$ ) [21].

Membrane treatment technologies provide the highest quality of biodiesel cleaning. At the same time, the equipment is expensive, requires high energy cost. Organic membranes are not resistant to solvents, and the lack of ceramic membranes lies in their fragility [3].

Consequently, the task of our research is: to check the effectiveness of biodiesel purification with wet methods; to establish optimal and rational parameters of biodiesel purification and disposing of its cleaning waste.

\section{Materials and methods}

The effectiveness of biodiesel washing was investigated during the processed of volumetric, bubble and aerosol washing.

Methodology of experimental study of biodiesel volumetric washing. For experimental study of volumetric washing the biodiesel is prepared with the use of potassium methylate, obtained from a ratio of methanol to $\mathrm{KOH}$ as 1 to 0.6 . The resulting biodiesel is then purified from methanol and neutralized with $1 \%$ aqueous citric acid solution at a neutralization rate of $5.5 \mathrm{ml}$ per $100 \mathrm{ml}$ of methyl ether.

In a glass of $300 \mathrm{ml}, 1 / 3$ of biodiesel after neutralization is added to $2 / 3$ of water. A glass with a tripod is placed in the thermostat TЖ-TC-01/16, which is set at a temperature of $40^{\circ} \mathrm{C}$. The mixing is carried out using a blade mixer with three blades on the shaft and a four-blade agitator with sloping blades. Mixer drive is carried out from the mixing device EOROSTAR digital (Fig. 1).

The rotation frequency of the shaft of the blade mixer is $100,200,300$ and 400 rpm. (at higher frequencies the formed funnel reaches the bottom of the glass), a four-blade mixer with sloping blades: 200, 350, 500, $650 \mathrm{rmp}$. The test time is 4 hours. Sampling of biodiesel to determine its alkalinity is carried out every hour. There is a replacement of contaminated water with the clean every hour.

Methodology of studying the efficiency of biodiesel foam washing. After preparation, purification and neutralization $1 / 3$ of biodiesel after neutralization and $2 / 3$ of water were poured in a flask of $300 \mathrm{ml}$. A nozzle with two entrances is installed in the neck of the bulb. Through one of the entrances to the flask tube with a 
titanium nozzle from the aquarium microcompressor air is injected, which is bubbled through a layer of water and biodiesel (Fig. 2), through the other the exhaust air is removed. The air flow rate is 20 and $60 \mathrm{~L} / \mathrm{h}$. The flask with a tripod is installed in the thermostat TЖ-TC-01/16. The research is carried out at a temperature of biodiesel 20,40 and $60{ }^{\circ} \mathrm{C}$.

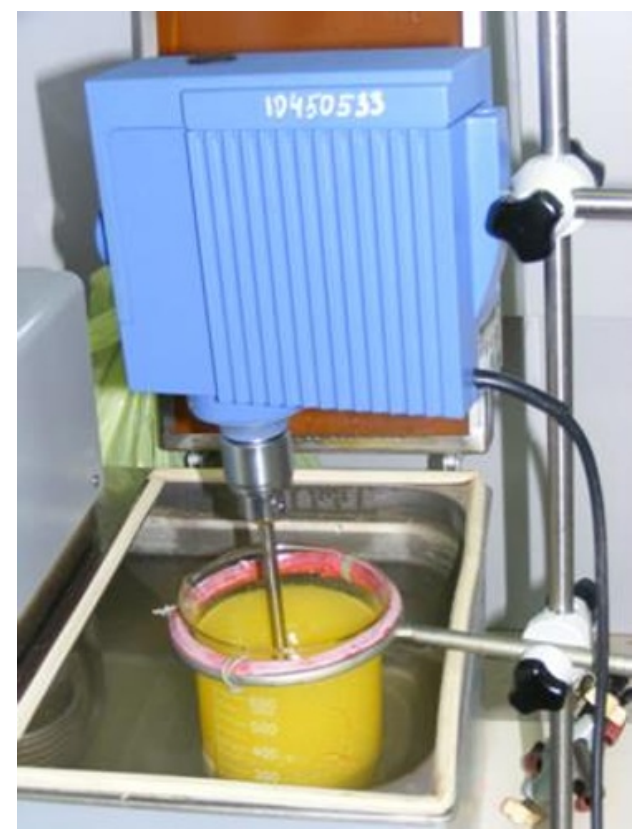

Fig. 1. The investigation of volumetric washing of methyl ether.

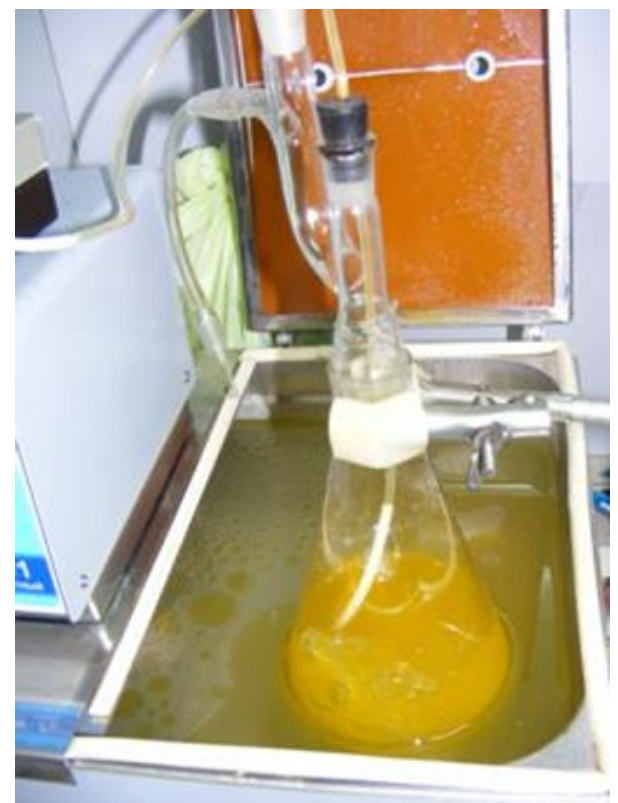

Fig. 2. The investigation of biodiesel foam washing process.

The test time is 4 hours. Sampling of biodiesel to determine its alkalinity is carried out every hour. There is a replacement of contaminated water with the clean one every hour as 
well.

Methodology of aerosol biodiesel washing investigation. After preparation, purification and neutralization, $300 \mathrm{ml}$ of biodiesel at room temperature is poured into an inverted 2liter PET bottle (without the bottom) with a cock for water drainage mounted in a lid (Fig. 3). There is a centrifugal full-groove sprayer "Disc and Core" by TeeJet above it (fig. 4), which consists of a case with one nozzle QJ17560A-NJB, bayonet cap CP 26277-1-NY, turbogenerator core (three types of turbulators: D-1-CER with one hole, DC-33-CER with two holes and DC-56-CER with four holes), a ceramic disk with a hole DCER-2 (diameter $-1 \mathrm{~mm}$ ) and a rubber sealant CP-18999. Water is sprayed into a PET bottle with biodiesel (Fig. 6) through a full-blown dispenser "Disc and Core" using a hydraulic pump designed from a refrigerator tank from the garden sprayer and compressor "Atlant" (from the refrigerator) (Fig. 5) to maintain a given pressure. Over time, stratification of biodiesel and water are observed. The stratification intensity increases with the vibration of the walls of the PET bottle (Fig. 7). Rinsing water as it accumulates periodically drains through the tap in the lid of the bottle into the container.

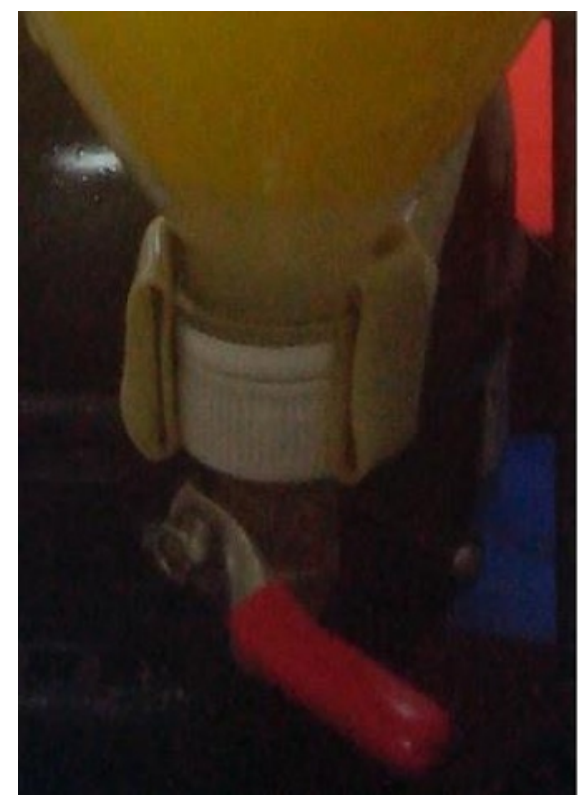

Fig. 3. The lid of the PET bottle with a cock for water drainage.
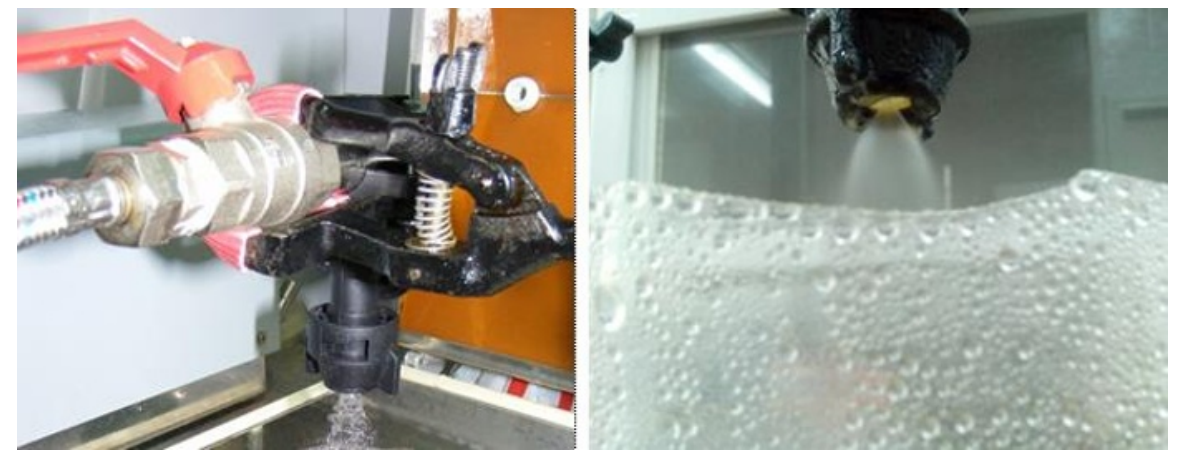

Fig. 4. Centrifugal full-strength sprayer "Disc and Core" by TeeJet. 


\section{ICoRES 2019}

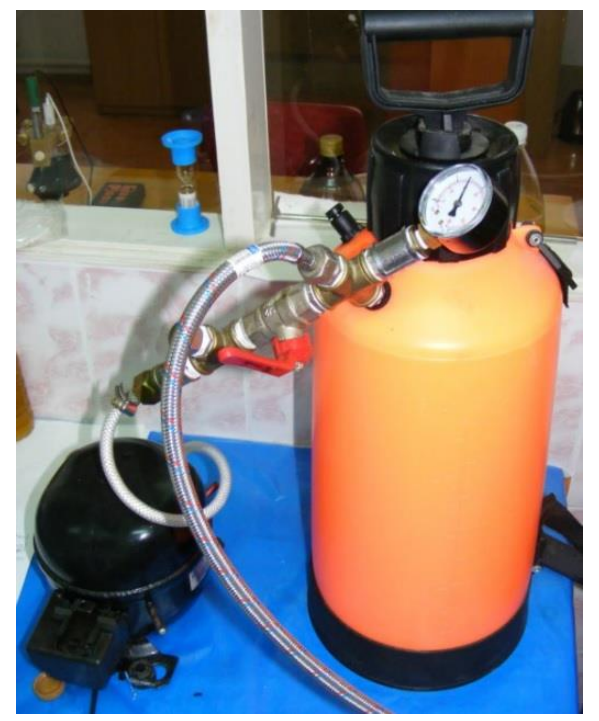

Fig. 5. Hydraulic pump on the basis of garden sprayer and refrigerator compressor.

a

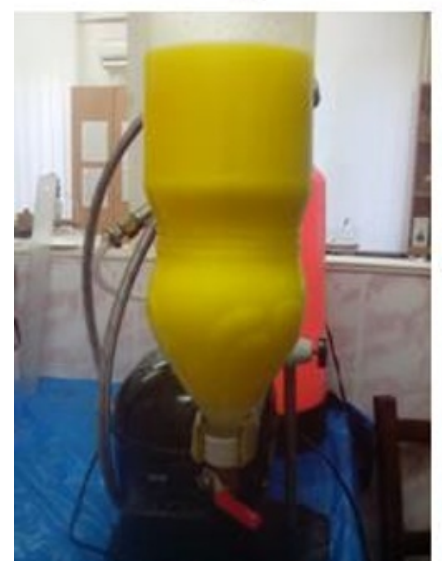

$b$

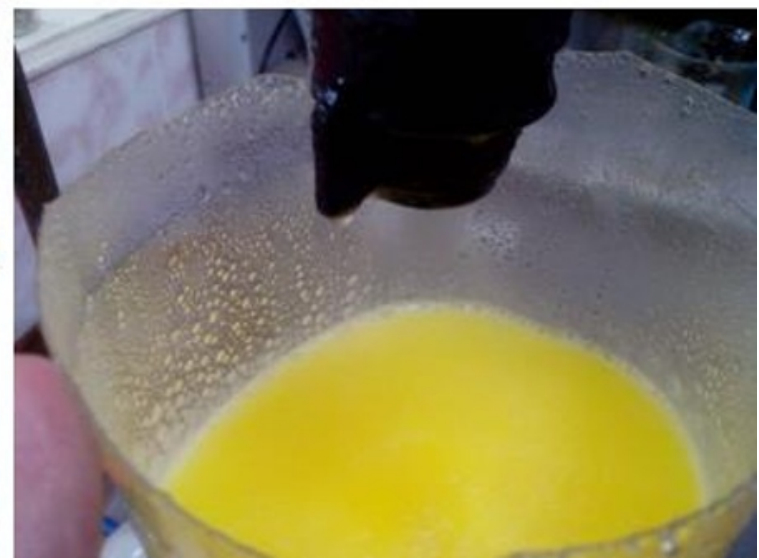

Fig. 6. Investigation of aerosol washing of methyl ether: $a$ - mixture of biodiesel and water; $b-$ process of water spraying over the biodiesel layer. 


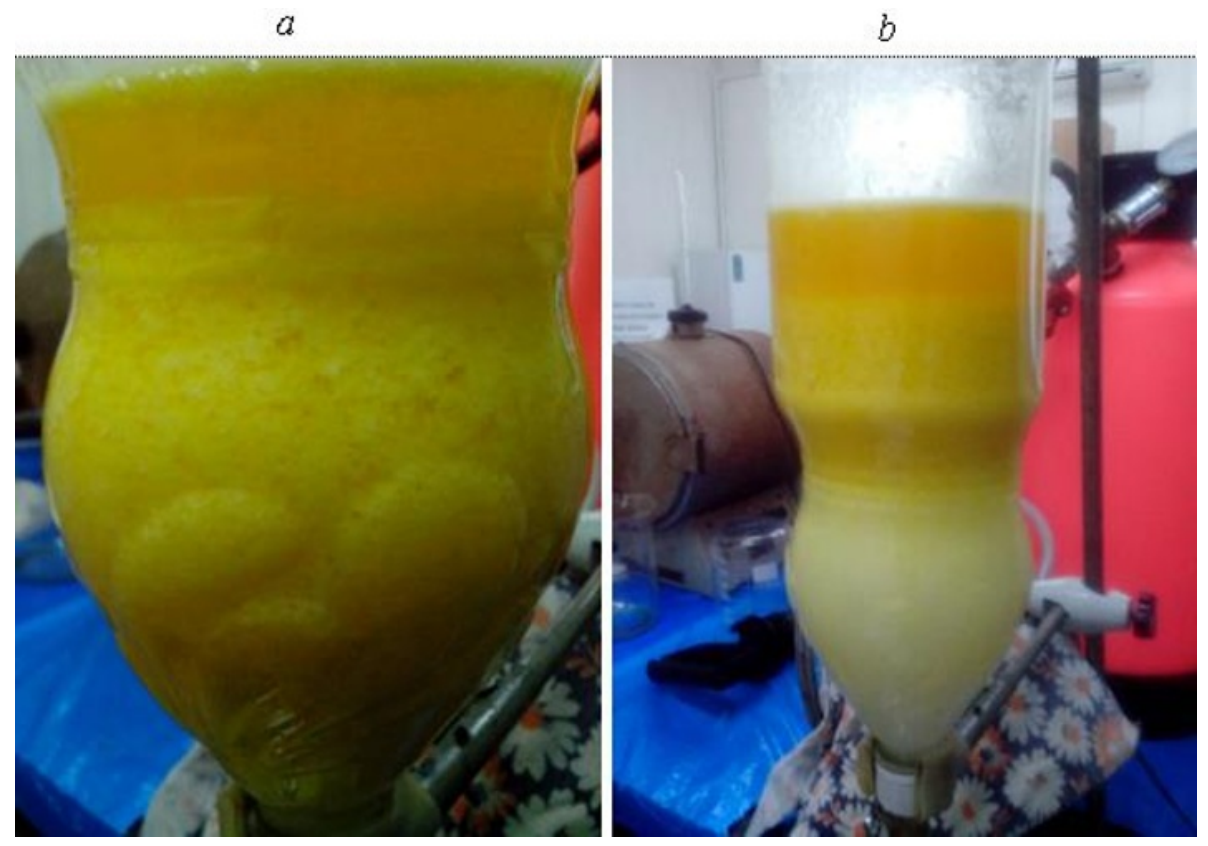

Fig. 7. Process of stratification during aerosol washing of methyl ether: $a$ - beginning; $b-$ completion.

The pressure is maintained within the range of 2 bars. Turbulators of three types are used: DC-31-CER with one hole, DC-33-CER with two holes and DC-56-CER with four holes.

The experiment time is 5 hours. Sampling of methyl ether to determine its alkalinity is carried out every hour.

\section{Research results}

Results of experimental studies of biodiesel volumetric washing. Use of a blade mixer with three blades on a shaft and a four-blade agitator with sloping blades. The dynamics of the alkalinity change of methyl ether is shown in Fig. 8, $a$ (for a three-blade agitator) and on fig. $8, b$ (for a four-blade agitator with sloping blades).

As it can be seen in Fig. 8, at volumetric washing with blade agitators, the alkalinity of biodiesel increases with time, which can be explained by the breakdown of plates of potassium citrate into smaller ones as a result of mechanical mixing and their poor transition from the biodiesel layer to the water layer.

At the same time, when using a standard blade mixer, the sharp increase in alkalinity of biodiesel is observed during the first hour of rinsing, later on alkalinity also slightly increases or stabilizes at an achieved level which significantly exceeds the level of alkalinity immediately after the neutralization of biodiesel.

When using an agitator with sloping blades, the alkalinity of biodiesel does not increase dramatically, but gradually and during the studied time of flushing exceeds the level of alkalinity immediately after the neutralization of biodiesel.

Consequently, volumetric flushing for four hours releases biodiesel from potassium citrate improperly. 


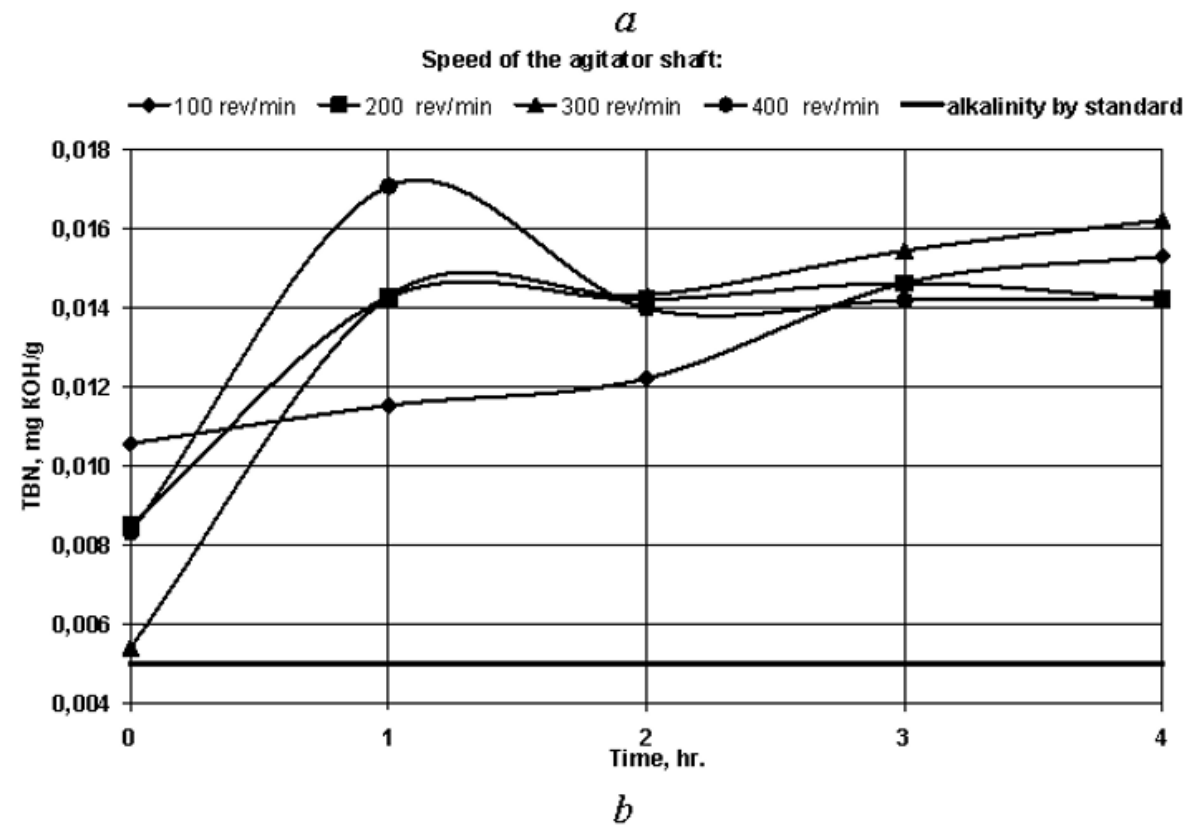

Speed of the agitator shaft:

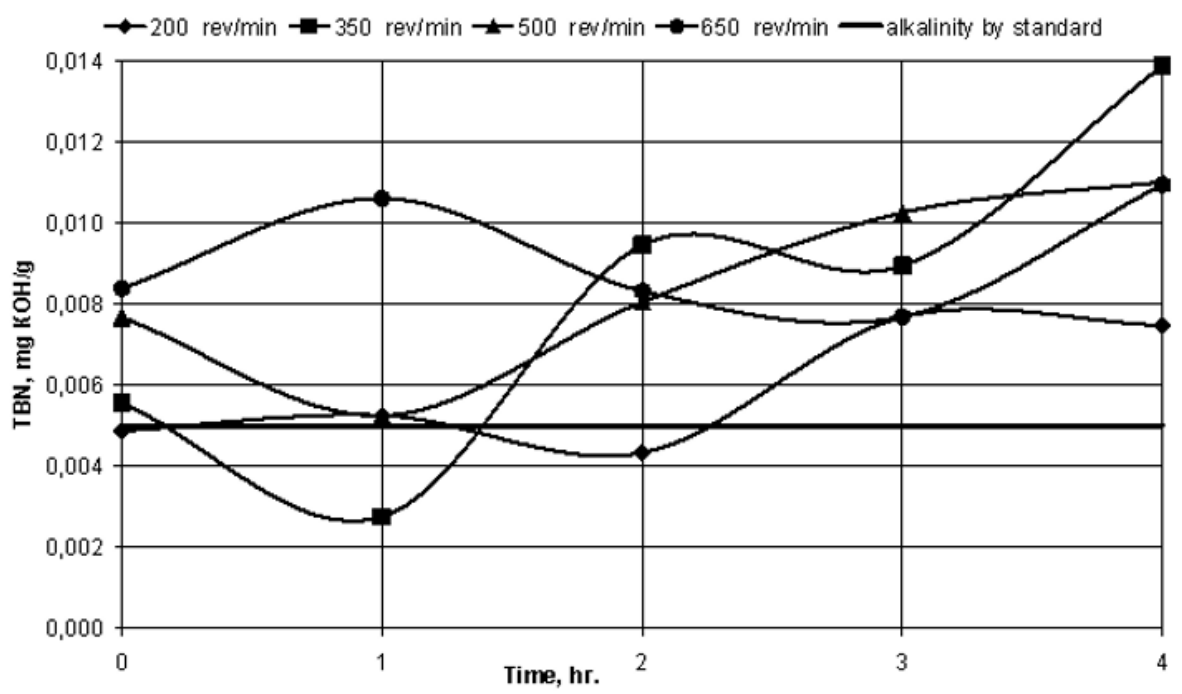

Fig. 8. The dynamics of the biodiesel alkalinity change with time during volumetric washing: $a-$ with the help of agitator; $b$ - with the help of four-blade agitator.

The results of experimental studies of foam washing of biodiesel. The dynamics of the change in alkalinity of biodiesel is shown in Fig. 9, $a$ (at an air flow of 20 liters per hour) and in Fig. 9, $b$ (at an air flow of 60 liters per hour).

As can be seen in Fig. 9, the alkalinity of biodiesel during foam washing in most cases is initially reduced during the first $2-3 \mathrm{~h}$. to a level not exceeding $5 \mathrm{mg} \mathrm{KOH} / \mathrm{kg}$, but then gradually begins to increase. At an air flow of 20 liters per hour after 4-hour washing the alkalinity of biodiesel exceeds the standard across the whole range of investigated temperatures. At an air flow of 60 liters per hour. after 4-hour washing the alkalinity of biodiesel, which was washed at $20^{\circ} \mathrm{C}$ and $60{ }^{\circ} \mathrm{C}$, is at the level of the standard, but shows a 


\section{ICORES 2019}

tendency to increase with further washing. Only rinsing at a temperature of $40{ }^{\circ} \mathrm{C}$ reduces the alkalinity of biodiesel below the standard.
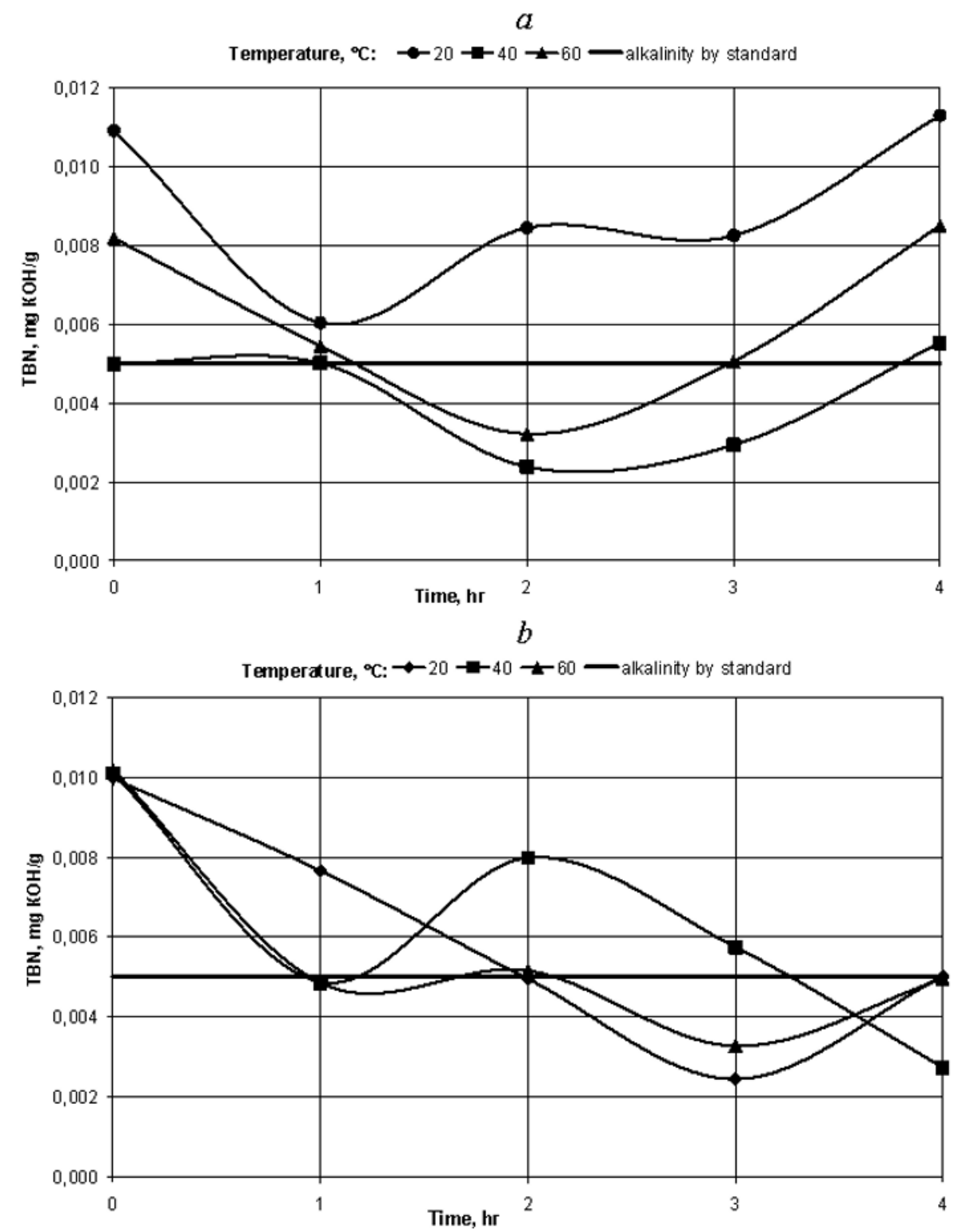

Fig. 9. The dynamics of alkalinity change of methyl ether in time during foam washing at an air flow of: $a-20 \mathrm{~L} /$ hour.; $b-60 \mathrm{~L} /$ hour.

Thus, during foam rinsing of biodiesel at air flow of $20 \mathrm{~L} / \mathrm{min}$. its alkalinity during 1-2 hours. of bubbling decreases by 2-3 times. Further bubbling is not feasible, since alkalinity does not decrease, but increases. With an air flow of 60 liters per hour. for 3-4 hrs. of bubbling, the alkalinity of biodiesel is reduced by 4.5 times, but thereafter, some of its growth is observed.

Results of experimental studies of aerosol washing of biodiesel. The dynamics of changes in alkalinity of biodiesel during aerosol washing is shown in Fig. 10. 
As it can be seen from Fig. 10, during the first two hours of washing the alkalinity of biodiesel is significantly reduced, but thereafter there is some increase in it with subsequent washing during 1-2 hours. Later on, at a $4-5^{\text {th }}$ hour of washing of alkaline biodiesel is gradually reduced to a level below $5 \mathrm{mg} \mathrm{KOH} / \mathrm{kg}$. The resulting alkalinity of biodiesel decreases by about 2 times, with a tendency to decrease it during a longer time of washing.

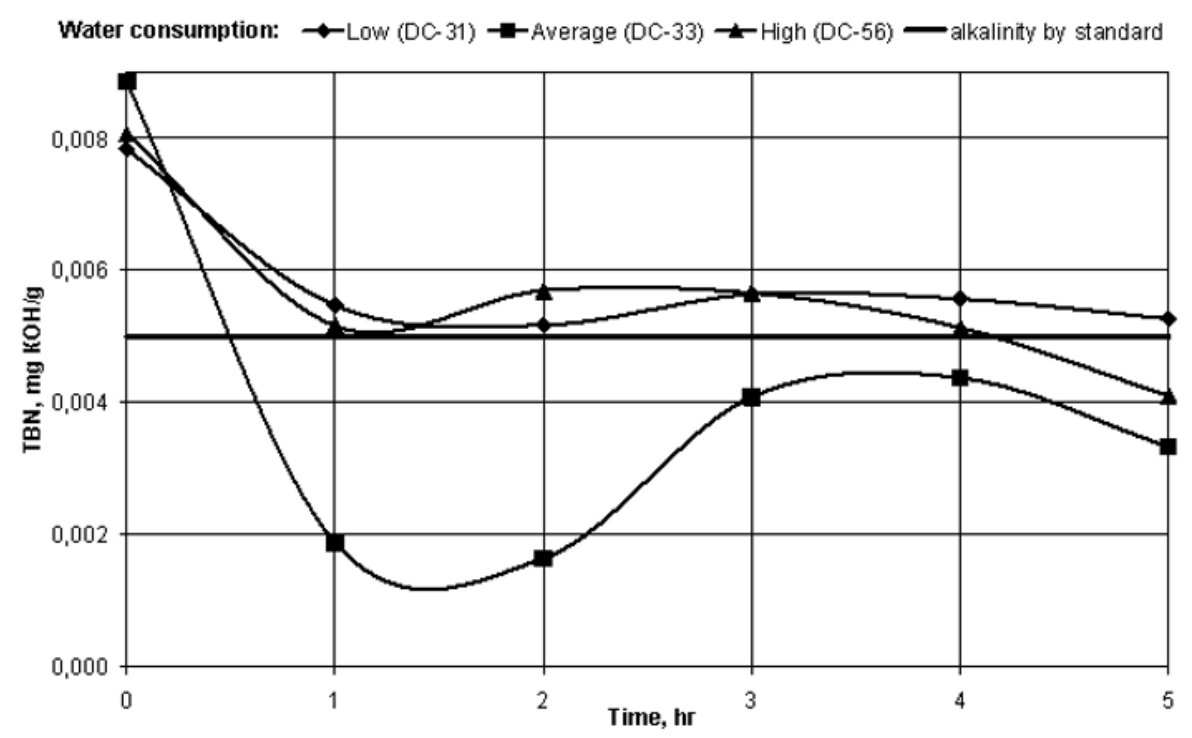

Fig. 10. The dynamics of alkalinity change of methyl ether in time during aerosol washing.

At fine-grained washing (turbogenerator DC-31) for $5 \mathrm{~h}$. the resulting alkalinity of biodiesel is only approaching the standard value of $5 \mathrm{mg} / \mathrm{kg}$, whereas with a mediumgrained (turbulizer DC-33) and a large-grained (turbulizer DC-56) at $5^{\text {th }}$ hour the rinsing reaches the value of $3,5-4 \mathrm{mg} / \mathrm{kg}$ at the same initial values, which corresponds to theoretical calculations.

When cleaning biodiesel waste remains: 15-20\% of crude glycerin from biodiesel output and about $2.5 \%$ of stock flow, which are difficult to recycle. Thus, with a rapeseed yield of $25 \mathrm{c} /$ ha out of 100 hectares of rapeseed, about 13 tons of raw glycerin and 2.2 tons of stock flow in the composition of 14.5 tons of wash water remain as waste when processing its seeds for biodiesel. It is advisable to dispose of these wastes by using them as a cosubstrate for biogas plants, which will double the output of biogas from the substrate based on cattle manure (from $0.71 / \mathrm{kg}$ to $1.41 / \mathrm{kg}$ dry organic matter).

\section{Conclusions}

One of the three methods of biodiesel washing studied can be recommended for practical use - aerosol washing, moreover, with medium- and large-grained washing to be carried out for at least 4-5 hours, while fine-grained - for a longer time. The use of waste from the purification of biodiesel as a cosubstrate in biogas plants will almost double the output of biogas, which will significantly reduce the payback period of biogas plants. 


\section{References}

1. S.P. Vysotsky, D.N. But, Collection of scientific works of the Lugansk National Agrarian University, 81, 230-233. (2008)

2. M. Alovert, US: M. Alovert, Biodiesel homebrew guide: everything you need to know to make quality alternative diesel fuel out of waste restaurant fryer oil, 115 (2007)

3. I.M. Atadashi, M.K. Aroua, A.R. Aziz Abdul, N.M.N. Sulaiman, Applied Energy, 88(12), 4239-4251, doi: 10.1016/j.apenergy.2011.05.029 (2011)

4. P. Nakpong, S. Wootthikanokkhan, Fuel, 89(8), 1806-1811, doi: 10.1016/j.fuel.2009.11.040 (2010)

5. J. Saleh, A.Y. Tremblay, M.A., Dube Fuel, 89(9), 2260-2266, doi: 10.1016/j.fuel.2010.04.025 (2010)

6. P. Cao, M.A. Dubé, A.Y. Tremblay, Biomass Bioenergy 32(11) 1028-1036 doi: 10.1016/j.biombioe.2008.01.020 (2008)

7. B.H. Hameed, L.F. Lai, L.H. Chin, Fuel Processing Technology, 90(4), 606-610, doi: 10.1016/j.fuproc.2008.12.014 (2009)

8. P. Jaruwat, K. Sangkorn, H. Mali, Energy Conversion and Management, 51(3), 531-537, doi: 10.1016/j.enconman.2009.10.018 (2010)

9. S.P. Vysotsky, V.A. Bagmet, Bulletin of the Donetsk National Academy of Civil Engineering and Architecture, 4(120), 104-107 (2016)

10. J. Wall, J. Van Gerpen, J. Thompson, Transactions of the asabe, 54(2), 535-541 (2011)

11. S. Banga, P.K. Varshney, Journal of scientific and industrial research, 69, 575-579 (2010)

12. M.C. Manique, B. Onorevoli, L.V. Lacerda, A.K. Alves, C.P. Bergmann, Biofuels-UK. 7(2), 155-161, doi: 10.1080/17597269.2015.1122473 (2016)

13. Yu.M.Plaksin, N.N. Malakhov, V.A. Larin, Moscow, Russia: KolosS, 760 (2009).

14. A.B. Fadhil, W.S. Abdulahad, International Journal of Green Energy, 13(6), 538-545, doi: 10.1080/15435075.2014.962034 (2016).

15. S.R. da Silva, N.J.A. de Albuquerque, R.M. de Almeida, F.C. de Abreu, Materials, 10(10), Article Number: 1132, doi: 10.3390/ma10101132 (2017)

16. Z.J. Predojevic, Fuel, 87(17-18), 3522-3528, doi: 10.1016/j.fuel.2008.07.003 (2008)

17. I.V. Shutsky, O.G. Galuzinsky, Sugar Ukraine, 1, 8-15 (2008)

A. Casas, M.J. Ramos, A. Perez, Chemical Engineering Journal, 220, 337-342, doi: 10.1016/j.cej.2013.01.042 (2013)

18. A.J.A. de Paula, M.Krugel, J.P. Miranda, L.F.D. Rossi, P.R.D. Neto, Quimica Nova, 34(1), $91-$ 95, doi: 10.1590/S0100-40422011000100018 (2011)

19. M.L. Savaliya, B.D. Dhorajiya, Separation and purification reviews, 44(1), 28-40, doi: 10.1080/15422119.2013.872126 (2015)

20. A.G. Balandina, R.I. Hangildin, I.G. Ibragimov, V.A. Martyasheva, Oil and gas business, 5, 336-375 (2015). 